\title{
Review of Mediation from the Social Constructivist Perspective and Its Implications for Secondary School EFL Classrooms in China
}

\author{
Xiongyong Cheng \\ Xinyang Agricultural College, 464000 No. 1 Nongzhuan Road, Xinyang City, China \\ Email: xiongyong@siswa.um.edu.my \\ Hua Cheng \\ Faculty of Foreign Languages, Henan University Minsheng College, 475001 Minglun Avenue, Kaifeng City, China \\ Email: woshichenghua@126.com

\begin{abstract}
This paper critically highlights the survey of the body of literature in favor of social constructivism to look at the changing views of teacher classroom performance, from which it seems more challenging for a teacher to help students construct knowledge than to instruct directly. The history of mediation is discussed with Feuerstein's 12 mediated learning experience features incorporated into Vygotsky's zone of proximal development on the basis of social constructivism. To address the proposed question, a methodological triangulation (i.e., observations $\&$ interviews) was applied for data collection regarding language teacher mediative practices. Based on the findings, a conclusion is drawn that most English as a foreign language (EFL) teachers among secondary schools in China are unable to mediate students' learning due to the deficiency of mediation and the fact that most Chinese EFL learners are weak at communicative competence in the target language. An EFL teacher's command of mediation knowledge plus his/her abilities to overcome situational constraints might result in the successful implementation of mediation strategies.
\end{abstract}

Index Terms - mediation, social constructivism, secondary school, implication

\section{INTRODUCTION}

From the perspective of learners' education quality facilitation, this study is expected to be important since most secondary school English as a foreign language (EFL) learners in China are exposed to limited linguistic knowledge attaching importance to language grammar and fail to express themselves orally and literally in EFL (Ye, 2007). The most successful foreign language teaching programs, however, should "involve the whole learner in the experience of language as a network of relations between people, things, and events" (Savignon, 1987, p. 236, cited in Chen, 2005, p. 3). Mediation provides learners with more opportunities for them to practice EFL systematically and render the language learning more effective (Williams \& Burden, 2000). In this regard, the implementation of mediation should take priority in language instruction (Feuerstein, 1990).

\section{LITERATURE}

People are accustomed to talking about constructivism in two forms: individual constructivism and social constructivism (Woolfolk, 2004). Individual constructivist approaches are related to how individuals establish elements respecting their cognition and affection derived from their psychological organ (Phillips, 1997). Thus, individual constructivism is known as psychological constructivism, of which Piaget is a preeminent representative (Paris et al., 2001). By contrast, social constructivism concerns the formation of communal knowledge of distinct schools and how the process of people's common cognition about the world is conveyed to other individuals of a socio-cultural community (Woolfolk, 2004). Vygotsky and Feuerstein are two dominant figures in the school of social constructivism (Palincsar, 1998).

\section{A. Vygotsky's Social Constructivism}

Vygotsky's "Three Principal Assumptions" is known as his greatest contribution to social constructivism (1978). The first assumption is that the community and its internal members play a central role by interacting with the individual in that individual's view of the world (Vasireddy, 2007). The second is the assumption that the tools, whose type and quality determine the pattern and speed of cognitive development, are involved in the surrounding culture and language and important adults (Vasireddy, 2007). The zone of proximal development (ZPD) is viewed as Vygotsky's (1978) third principal assumption, conceptualized as "the distance between the actual developmental level as determined by 
independent problem solving and level of potential development as determined through solving under adult guidance or in collaboration with more capable peers" (p. 86).

According to the ZPD, at the outset of a learning process, the teacher is to undertake most of the task before the teacher and students assume the collaborative duty (Schunk, 2000). The teacher gradually reduces the help as scaffolding until students can perform alone since they become more capable (Campione et al., 1984). "Students are challenged to learn within the bounds of the ZPD, which is altered as they develop capabilities" (Schunk, 2000, p.245).

\section{B. Feuerstein's Mediation}

Not each interaction involving a task, learner, and mediator possesses a quality of mediated learning experience (MLE), so a system of the MLE criteria is developed to distinguish levels of MLE interactions (Feuerstein, 1980). Feuerstein proposes 12 indispensable parameters for evaluating the quality of MLE interaction as shown in Table 1, in which he believes that the 12 criteria represent 12 different ways of mediation for the teacher to conduct. The first "three criteria are also considered universal, in the sense that they can be present in all races, ethnic groups, cultural entities, and socioeconomic strata" (Seng et al., 2003, p. 36). By contrast, "the remaining nine criteria are considered situational because they need not always be present in every MLE” (Seng et al., 2003, p. 36). Given the need of this study, the operational definitions of universal mediation and situational mediation are drawn on, referring to the first three MLE criteria and the remaining nine respectively.

TABLE 1

FEUERSTEIN'S MLE CRITERIA (1980)

\begin{tabular}{|c|c|}
\hline Parameter & Conceptualization \\
\hline 1. Significance & $\begin{array}{l}\text { The teacher makes students realize the importance of a learning task so that they can look at the significance } \\
\text { of the task to their own and in a broader cultural context. }\end{array}$ \\
\hline $\begin{array}{l}\text { 2. Purpose beyond the here } \\
\text { and now }\end{array}$ & $\begin{array}{l}\text { Explains to learners how conducting a learning activity will help them in the future beyond the moment and } \\
\text { situation at present only. }\end{array}$ \\
\hline 3. Shared intention & $\begin{array}{l}\text { In presenting a task, the teacher must make instructions clear and ensure the intention is understood and } \\
\text { reciprocated by learners. }\end{array}$ \\
\hline 4. A sense of competence & Fosters learners' feelings of competence and capability of learning. \\
\hline 5. Control of own behavior & Encourages students to be autonomous by self-controlling their learning procedure. \\
\hline 6. Goal-setting & $\begin{array}{l}\text { Teaches learners how to establish achievable targets and to locate approaches for the purpose of realizing } \\
\text { them. }\end{array}$ \\
\hline 7. Challenge & Helps learners to develop internal needs to face challenges and to seek for new challenges in life. \\
\hline 8. Awareness of change & $\begin{array}{l}\text { Stimulates learners to monitor changes in themselves and to understand the fact that humans are changeable } \\
\text { all the time. }\end{array}$ \\
\hline $\begin{array}{l}\text { 9. A belief in positive } \\
\text { outcomes }\end{array}$ & $\begin{array}{l}\text { Urges learners to assume there is always the possibility of finding a solution, even when faced with an } \\
\text { apparently intractable problem. }\end{array}$ \\
\hline 10. Sharing & $\begin{array}{l}\text { Invites learners to share behaviors and to perceive that it is advisable for some problems to be addressed } \\
\text { collaboratively. }\end{array}$ \\
\hline 11. Individuality & Helps learners realize their individual characteristics in terms of their unique aspects. \\
\hline 12. A sense of belonging & $\begin{array}{l}\text { Aids learners to establish a consciousness of pertaining to the whole class community in the process of the } \\
\text { completion of the task. }\end{array}$ \\
\hline
\end{tabular}

\section{Missing Link: From Vygotsky to Feuerstein}

Vygotsky (1978) and Feuerstein (1980) seem to facilitate each other in effectively important manners as regards their works since Vygotsky utters the ZPD, a location where the probability of enhancement of a learner's abilities is able to be seen. Lantolf (2000) asserts that the ZPD is where social forms of mediation are performed and realized. Feuerstein's MLE describes what comes about within the ZPD centering on a mediator's helping learners get through this special zone and obtain their competence development in the zone eventually. Once students receive high-quality mediated learning in the school setting, they will have some grasp on how to learn for the future, at least tacitly and imperceptibly (Feuerstein, 1980). Vygotsky believes that human "higher mental processes are functions of mediated activity" (cited in Seng et al., 2003, p.6), but even then "the role of the human mediator is not fully elaborated within [Vygotsky's] theoretical framework" so that the theoretical gap is bridged with the help of "Feuerstein's (1990) theory of mediated learning, which assigns the major role to a human mediator"( Kozulin, 1994, p.284, cited in Seng et al., 2003, p.7). The application of mediation incorporated into the ZPD is expected to be the strongest rationale to explore its implications for EFL classrooms in China respecting the execution of mediation.

\section{THE PROBLEM}

China is historically an authoritarian society, and the classroom is heavily influenced by the Confucian model of the explicitly stratified social hierarchy, for which EFL instruction is teacher-centered, textbook-centered, and grammarcentered (Liao, 2003). Most secondary school EFL teachers in China notice that their students come across numerous obstacles in speaking and writing (Kang \& Wang, 2003). This phenomenon is ascribed to the insufficiency of proper instructional strategies applied in the language classroom ( $\mathrm{Ng} \&$ Tang, 1997). It is assumed that this study could push the current pedagogical reform by identifying EFL teachers' implementation of mediation for theoretical verification and empirical support of students' all-round development. This conduct, for one thing, adapts to the requests of China's 
new National Standards of English Curriculum for Basic Education (hereafter referred to as Curriculum Standards) established on the rationale that the school role is no longer limited to instruction since teachers should undertake responsibilities and obligations in other possible aspects apart from teaching duties (Ministry of Education of China [MOE], 2001). For another, as teachers are decision-makers in handling the class process, the teacher role is viewed as a crucial issue to be addressed regardless of whatever educational settings, potentials, and problems (Brown, 2001). As such, this study tries to fill in the gap in the existing literature on the extent of teachers' adherence to desired requirements in EFL instruction.

\section{QUESTION}

This paper aims to explore the potential effectiveness of mediation on secondary school EFL classrooms in China. To fulfill this target, one question that follows is proposed: How does mediation impact on secondary school EFL teacher roles in China?

\section{Previous Research on Mediation}

Previous research indicated that most language teachers had little knowledge of mediation, which affected their implementation of mediation in the classroom (e.g., Grosser \& Waal, 2008; Guo, 2004; Sun, 2007). In such studies, teachers' desire for the role of mediator was strong as they were aware of the effectiveness of mediation (Sun, 2007). However, they tended to focus their attention on knowledge transmission, and students were dissatisfied with teachers' mediation activities (Guo, 2004). Much research on mediation has been conducted to compare the consistency between teachers' attitudes towards mediation and their classroom practices (e.g., Cheng, 2011; Grosser \& Waal, 2008; Shen, 2008). Researchers adopt Williams and Burden's (2000) Mediation Questionnaire to testify teachers' attitudes and behaviors based on the 12 MLE tools. In most cases, the difference is significant between teachers' attitudes and behaviors with reference to the means in the scale of the 12 MLE features. Then, teachers and students are observed and interviewed so that their classroom practices and attitudes towards mediation can be further confirmed.

While exploring teachers' implementation of mediation, researchers have revealed the existence of a gap between teachers' behaviors and students' feelings about mediation. H. T. Yang (2006) reports in his research that "as for teachers' mediative classroom behaviors, teachers' self-assessment is overtly above students' evaluation to them" (p. 83). Students anticipate that EFL teachers can help them develop self-confidence to learn English well, teach them effective learning strategies, set their own learning goal, and facilitate their social enhancement (Lai, 2004). Students are inclined to learn autonomously with the help of teachers' mediation in the classroom (Guo, 2004).

\section{INSTRUMENTS}

\section{A. Observations}

A purposive sampling technique was administered in this study. Three EFL teachers were non-randomly selected for the field observations who got informed that the observation was to recognize what happened in their classroom rather than a performance evaluation. An observation worksheet (Appendix A) was designed identifying the extent of the teacher's execution of the 12 MLE features in the Likert-type scale. A technician was employed to video-record the observations and the subsequent interviews with the participants. In process of the observations, the researcher played the role of non-participant observer, and the video-recorded observations were then fully transcribed to identify focal themes (Creswell, 2005).

\section{B. Interviews}

Interviewing was seen as an opportunity for the teachers to utter opinions related to their profession, which was a crucial approach for the researcher to check the accuracy of the impressions he had gained through the observation (Fraenkel \& Wallen, 2007). A semi-structured interview protocol (Appendix B) was guided by a set of open-ended questions as loosely structured questions allowed participants more freedom to relate more of what was significant to them (Y. Li, 2004). Opinions by a related panel were sought to verify the interview accuracy and appropriateness. To eliminate potential barriers by EFL, the participants were interviewed in Chinese, the mother tongue of both the interviewees and the interviewer. The interviews were video-recorded and partially transcribed to highlight the main subjects in relation to this study.

\section{PARTICIPANTS}

The target population of this study composed of all China's secondary school EFL teachers to which the researcher prefers to generalize is rarely achievable (Fraenkel \& Wallen, 2007). The research was conducted in Henan province located in eastern central China for the accessible population. In the case study, generalization is not the ultimate target to pursue, so purposeful sampling seems an ideal alternative in discovering, understanding, and obtaining the most effective insights (Merriam, 1998). Qualitative research via maximum variation sampling with rich accounts on participants' experience "may be epistemologically in harmony with the reader's experience" (Stake, 1978, p. 5) and 
insightful as "maximum variation sampling can yield detailed descriptions of each case, in addition to identifying shared patterns that cut across cases" (Hoepfl, 1997, p. 52). The selection was characterized by the rich background of three participants with respective pseudonyms---Alice, Jane, and Moor as shown in Table 2.

TABLE 2

IDENTIFICATION OF THREE PARTICIPATING TEACHERS

\begin{tabular}{|l|l|l|l|l|l|l|l|}
\hline Name & Gender & Age & Degree & Teaching years & Grade & Class size & School site \\
\hline Alice & Female & 44 & Bachelor & 22 & Jr. grade 1 & 70 & Suburb \\
\hline Jane & Female & 41 & Bachelor & 17 & Jr. grade 2 & 50 & City \\
\hline Moor & Male & 24 & Bachelor & 3 & Sr. grade 3 & 51 & Suburb \\
\hline
\end{tabular}

\section{FINDINGS}

\section{A. Case Study of Alice}

The text of the first observed lesson Alice taught was Section B, Topic 3, Unit 3 of Project English 1A for junior grade one students with the title "What would you like to drink?". The text focused on functional items like "having meals" and "ordering food and drinks". It was composed of four segments with the subtitles 1a "Look, listen, and say", $1 \mathrm{~b}$ "Pair work", 2a "Listen, read, and say", and 2b "Pair work". The text of the second lesson was Section B, Topic 2, Unit 4 of Project English 1A with the title "Would you like to go for a picnic?". It consisted of five sections with the subtitles 1a "Listen, read, and say", 1b "Pair work", 1c "Work alone", 2a "Listen, read, and say", and 2b "Work alone".

The activities Alice conducted have indicated the focus of interest in this case study. The observation worksheet (Appendix A) aimed to detect the extent of the teachers' execution of the 12 MLE features in the Likert- scale from not at all to very much. Possible mediative parameters manifested in Alice's lessons were analyzed subsequently except that "significance" and "purpose beyond the here and now" were not much displayed.

1) Shared intention: Alice made her instructions clear while presenting tasks to ensure that her intention was fully understood by asking the students "Are you clear?" repeatedly. Not until the students made an affirmative answer did she continue with the contents.

2) A sense of competence: In the class, Alice encouraged her students to participate by drawing on possible stimulating measures. The whole class as well as the teacher clapped for the volunteer respondents. By doing so, Alice was making the students perceive themselves as capable of learning. As Williams and Burden argue (2000),

If learning is to be successful, it is crucial that teachers establish in their classrooms a climate where confidence is built up, where mistakes can be made without fear, where learners can use the language without embarrassment, where all contributions are valued, and where activities lead to feelings of success, not failure. (p. 73)

3) Control of own behavior: Alice offered her students revision summaries to develop their regulating learning abilities the moment they learnt new knowledge. She also gave them adequate opportunities to recite the dialogues promptly. In this manner, Alice intended to push her students to control their own learning after being exposed to new knowledge so that they would become not only effective but independent learners. In Williams and Burden's words,

Feelings of competence are necessary but not sufficient for learning to be effective; learners also need to become competent, that is, they need to learn the necessary skills and strategies in order to take control of their own learning. (p. 73)

4) Goal-setting: Alice assisted her students in setting short-term and long-term goals for themselves in the process of conducting learning activities, like the above-mentioned short-term memory of the dialogue learnt minutes before. She likewise set goals for the backward students to catch up with the more advanced ones. However, "children who set their own goals in any learning activity are more likely to achieve those goals than ones that are set for them" (Werkhoven, 1990, cited in Williams \& Burden, 2000, p. 74). Hopefully, Alice can mediate her students' learning better by making them set their own goals in the future.

5) Challenge: Alice encouraged the students to volunteer for the activities, which seemed challenging to them when there were some visitors. As was noted, it was also a challenge for Alice's students to recite the dialogues within minutes. At this point, Alice encouraged the shy and less confident students to face the challenges like this:

Who will have another try? Is there anybody else? (Pointing to one side of the class) Just now, some pairs of students on this side performed very actively, and they could all raise hands constantly. Hence, (pointing to another side) the students on that side of the class cannot fall behind. Be brave and voluntary to answer my questions. Okay, Liu Yue and your partner, please. (Alice, Observation Video-recording 1, October 9, 2009)

From this excerpt, it seems to be deduced that the challenges of Alice's students were "within their current capabilities" since they managed to accomplish the tasks through efforts (Williams \& Burden, 2000, p. 75). More importantly, Alice intended to have all the students involved in the collaborative activities. As Williams and Burden suggest,

No matter how much information a teacher may have about a group or even individual learners, it is virtually impossible to match each learner with the right level of task without involving the learners themselves in the process. Since the ultimate goal of mediated learning experiences is to produce independent learners and problem solvers, 
increasing the involvement of the learners in all aspects of the learning process should be encouraged at every opportunity. (p. 75)

6) Awareness of change: Alice attended to the students' self-development when helping them set goals regardless of surpassing themselves or others, implying that she focused on the students' change at all times. For this sake, Alice tried to present the students' changeable characteristics worth noticing as shown in the following account:

While Guangchao is hurt in the arm, he insists on studying in school. His attitudes towards studies are really positive. He is studying harder and has made greater progress in studies recently. In the past, I praised him several times, but he is still worth praising as I think his learning spirit praiseworthy. (Alice, Observation Video-recording 2, October 29, 2009)

When mentioning Guangchao's change, Alice highlighted his academic advances and learning attitudes. However, it could be better for her to help the students self-assess changes in themselves as it was viewed "as equally important to foster the ability to self-evaluate if we are to produce autonomous learners" (Williams \& Burden, 2000, p. 76).

7) A belief in positive outcomes: Any criticism to the students from Alice was never heard since she approved any trivial progress they made, even when they gave incorrect answers. Alice was always listening to the students' responses with a smile and fixing her believing eyes on the respondents. This could empower the students with confidence. She taught them to preview the related contents ahead of the class from which they could reap due benefits. Even if the students encountered intractable problems, she convinced them that there would be positive outcomes so long as they did their best.

8) Sharing: Alice's students had sufficient opportunities to accomplish pair and group work, during which they learnt approaches to solving problems. It could be said that the interaction between the teacher and students or among the students became the soul of Alice's class. This led to the students' recognition that team work was indispensable in their future studies since "sharing and working co-operatively are a vital part of our social existence, the absence of which can result in cognitive difficulties and a very idiosyncratic view of the world" (Williams \& Burden, 2000, p. 77).

9) Individuality: Alice was acquainted with her students and assessed the performance of the individuals with a clear aim. In Alice's words,

There are 70 students different in personality in the class. I am used to getting each of them involved in interactions between the teacher and students to fulfill the activities designed with reference to their personal characteristics. If they answer correctly, it will help them to perform better next time. They will also build self-confidence and catch up with other more advanced mates gradually. (Alice, Interview 2, October 29, 2009)

In the first observed class, Alice required her students to discuss their likes and dislikes about food and drinks, counting as an approach for the students to display their own uniqueness. Alice seemed to keep in mind the file of each of her students through the frequent exposure with them in the classroom and office. She allowed each of the students adequate opportunities to display their uniqueness by expanding the coverage of the students' participation. As Williams and Burden suggest (2000),

The language classroom is a place where this sense of individuality can be fostered in various ways through the tasks given, the teacher's actions and the climate created. Learners can be encouraged to express their own individuality through the foreign language. (p. 79)

10) A sense of belonging: Alice's students had a strong sense of belonging to the whole class which was observed to work as a team all the time. Alice often said "Girls, come on" or "Boys, don't fall behind" to get the whole class involved and to help foster their sense of belonging. She was trying to encourage a sense of belonging in her students by pushing them to contribute to the accomplishment of the task. Alice, however, would be able to mediate her students a bit better should she make the students' sense of belonging become their internal need. Williams and Burden (2000) recommend:

It is important to remember that the impetus for a community feeling must come not only from the teacher but from the learners as well. An example might be engaging in a whole-class project like a class newspaper where everyone has a contribution to make and no one is left out. (p. 79).

To sum up, Alice mediated a large class by (a) helping the class carry out pair/group work, (b) conducting the lessons skillfully, (c) managing the classroom effectively, (d) arousing all the participations' enthusiasm, and (e) applying rich body language. All these made it possible for her students to cooperate actively. Alice performed better in executing "shared intention", "a sense of competence", "control of own behavior", "challenging", "a belief in positive outcomes", "sharing", and "individuality". The implementation of "goal-setting", "awareness of change", and "a sense of belonging" remains to be improved. Alice was thus playing a situational mediator by and large.

\section{B. Case Study of Jane}

Jane provided the current study with two lessons applying the third volume of Project English. The text of the first lesson was Section C, Topic 1, Unit 2 of Project English 2A for junior grade two students titled "You had better see the doctor". The teaching aims were to (a) describe an affair with the information provided by the pictures and the words, (b) write a note for leave, and (c) remind the class to care about their safety in daily life. The second was the revision lesson of Topic 2, Unit 2 with the title "I must ask him to give up smoking" of Project English 2A, in which there were two revision sections concerning the key phrases and synchronous writing about Topic 2 without the teaching requests or procedure. 
Based on the teaching plan notes and transcripts of Jane's observed lessons, it could be seen that Jane seemed to conduct "shared intention", "control of own behaviour", and "individuality". However, Jane preferred to give instructions in Chinese sounding a little harsh like orders. While Jane's students understood her instructions, it was impossible for her to mediate the students' EFL learning in the Chinese context. As Williams and Burden (2000) put it,

One challenge to the language teacher, therefore, is to find ways of conveying clear intentions through the target language, and, equally importantly, of checking that these intentions are understood and reciprocated. Common ways of doing this are demonstrating while explaining, asking learners to repeat instructions, or asking a group to demonstrate while the teacher explains what to do. (p. 72)

Unfortunately, Jane did not apply other ways to "share intentions" but to speak Chinese only. She "mediated" the students' "control of own behaviour" by assigning them homework to accomplish out of class. The students had to follow her strictly in terms of the requirements of their work, which went against the cultivation of their autonomous learning. Jane seemed acquainted with her students but failed to treat them differently according to their respective personalities. Instead, in her words, "I often divide all the students into small groups according to their seat order rather than their levels in English, considering that the students do not need to move their chairs or desks to and fro" (Jane, Interview 2, October 29, 2009). This would generate a growing polarization between the advanced and backward students. It was not surprising that the backward students in Jane's class wanted to abandon EFL learning.

The two lessons Jane taught were therefore traditional and featured by teacher-centeredness and grammarcenteredness to be illustrated in the following account.

1) Teacher-centered instructor applying Chinese as a medium of instruction: Jane tended to incorporate interactions into her teaching, but these were practiced in a mechanical way. Jane was experienced in presenting the language points, but she failed to show the awareness of the students' individuality. She appeared too eager to correct their errors before they finished replying, so her students were obedient and inactive. Many of them were not really involved in the teaching activities. In the class, Jane was relied on as the main source of academic learning in which the students had no opportunities to regulate their learning. There was no lack of activities and learning tasks which, however, were entirely taken in Jane's hands for the completion of instructional contents. Feuerstein (1980) claims that "mediation involves interaction between mediator and learner, and that the learner is an active participant in the process" (cited in Williams \& Burden, 2000, p. 68). There was no really effective exchange of information since Jane controlled the whole class and made them passive knowledge-receivers (Yang, 2003).

In addition, Jane could not speak English fluently nor correctly sometimes. She almost talked in Chinese throughout the class except a little classroom English like "okay/very good/sit down, please".

2) Grammar-translation-based spoon-feeder: Jane was skilled at interpreting language structures and functions via grammar-translation, keeping the students exposed to literacy materials and translating English into their mother tongue (Larsen-Freeman, 2000). So the students learnt how to read and write English through grammar-based translation at the cost of listening and speaking (Chen, 2005). Jane viewed that she was performing better than other colleagues in this regard since she helped the students review the knowledge they had learnt before. As she put it,

The other teachers in my school seldom conduct revision lessons. Their students make notes each time they conduct a new lesson and write the main contents on the blackboard. The students then revise the notes that they have taken in the class for the coming examinations. (Jane, Interview 2, October 29, 2009)

On the whole, Jane was a grammar-translation-based knowledge spoon-feeder in the observed lessons as she was "spoon-feeding" knowledge to the students viewed as the "containers" or "warehouses", "accepting knowledge passively without thinking” (Lewin et al., 1994, p. 170).

\section{Case Study of Moor}

Moor's first lesson was on the revision of the text "Chuck's friends" in Unit 1, Book 1A of Senior English for China, which tells a story on a manager who is occupied with his work all day and fails to spend time with his friends. After a flight accident, he begins to rethink his life and understands real friendship. However, Moor did not explore humanistic implications from the text theme "Good friend". In the second lesson, Moor summarized the uses of the seven words in Units 7-8 of Student's Book 1B and then dealt with the synchronous exercises designed on the use points of the seven words. He interpreted the key words clearly without referring to the teaching plan. Moor could have availed himself of this opportunity to help the students form learning strategies, for instance, how to summarize word functions and revise language points just like he performed in this lesson, but he did not.

Moor was teaching what the grade three students had learnt two years before. The two observed lessons should have been the revision series. Moor, however, was observed to be like teaching a new text. For example, he need not have introduced the background of the text "Chuck's friend" in the revision class. While Moor was a green hand, his instruction was rigid as he confined his roles to a spoon-feeder, knowledge transmitter, and non-standard bilingual speaker as illustrated in the coming account.

1) Spoon-feeder: In the first lesson, like the case of Jane, Moor was observed to be spoon-feeding knowledge to the class, for he controlled everything happening in the classroom. An excerpt of the transcript of the first lesson is expected to show evidence:

$\cdots$ 
T: There is a question for you: "What happens to Chuck?" You can get the answer from the first paragraph. Huang Zhi, please.

S1: "Chuck is on a flight across the Pacific Ocean when suddenly his plane crashes."

T: Look at the second paragraph. I have another question for you: "What does Chuck learn about himself?" You may spend one minute finishing this task. (About 20 seconds later) Fan Mengchen, please.

S2: "He realizes that he hasn't been a very good friend because he has always been thinking about himself."

T: Another question for you: "What does Chuck learn about friendship?" You can get the answer from the same paragraph. Okay, also one minute for you. (About 30 seconds later) Wei Yang, please.

S3: "Chuck understands that friendship is about feelings and that we must give as much as we take."

T: Okay, sit down, please.

(Note: $\mathrm{T}=$ teacher; $\mathrm{S}=$ student)

(Moor, Observation Video-Recording 1, October 8, 2009)

As an impatient answer-giver, Moor failed to perceive students' thinking was indispensable for their learning process and that giving students' thinking time was necessary for the best development (Fisher, 2005). Instead, Moor was too anxious to tell the students the ranges of the answers before they tried, so his students gradually became "outsiders" of learning.

2) Grammar-based knowledge transmitter: In the second lesson, Moor taught with a revision exercise-book designed as per the requests of the mandatory textbook. He seemed to play the role of transmitter through grammar-translation due to the two factors that follow. First, Moor focused his attention on teaching vocabulary only "in the form of lists of isolated words" (Prator \& Celce-Murcia, 1979, p.3, cited in Brown, 2001, p.16), which is among "the major characteristics of grammar-translation" (Brown, 2001, p. 16). The information exchange between Moor and the students was ineffective with no information gap as the interactive questions originated from the exercise book whose answers Moor and his students had known beforehand (Johnson \& Morrow, 1981). Moor's teaching centred on the precise and elegant uses of EFL, but the entire instruction never went "beyond transmitting knowledge" (Mok, 2001, p.161, cited in Zeng, 2005, p.43). Second, Moor's teaching design was almost identical with the exercise book except for a few example sentences. Moor, in a sense, was transmitting knowledge from the exercise book to the students.

3) Non-standard bilingual speaker: Moor did not speak standard Chinese or English. The application of grammartranslation contributed to his poor pronunciation in English since "little or no attention is given to pronunciation" in the grammar-translation classroom where "classes are taught in the mother tongue, with little active use of the target language" ( Prator \& Celce-Murcia, 1979, p.3, cited in Brown 2001, p.16). For the most part, Moor talked in Chinese and translated his English instruction orders into Chinese. He preferred classroom English like "okay/good/thank you/sit down, please". Interestingly, in the class, most of Moor's students liked to speak the local Chinese dialect.

The field notes, observation sheet, and transcripts regarding Moor's extent of mediation implementation show Moor partially mediated "shared intention" and "goal-setting". Nevertheless, Moor failed to really share his intention with the students since he preferred to give instruction orders in Chinese. It was impossible for him to mediate the students' EFL learning in the Chinese context. As regards "goal-setting", Moor remarked that he was ready to help the students establish goals outside the class occasionally, which was weak in the evidence since he was observed not to.

\section{DisCUSSION}

\section{A. Alice's Role of Situational Mediator}

Alice was experienced in managing the classroom and had abilities to involve each of the students in the tasks. She was encouraging and showed positive attitudes towards teaching her students. She acted as the role of mediator in many ways such as helping the students share and develop a sense of belonging and a strong belief in positive outcomes. She also gave more positive feedback rather than criticisms respecting the students' performance. Even when she was correcting their errors, she could draw on a more reasonable and acceptable manner. She designed the adequate tasks for the students to participate in by allowing them opportunities for collaborative learning. As well, she showed much concern for the individuals and offered them constructive suggestions and realistic goals.

Based on the correct cognition of situational mediation and no obvious situational constraints, Alice played a situational mediator better due to not mediating "significance" and "purpose beyond the here and now" perfectly. Of the 12 mediative tools, Alice mediated best the students" "shared intention", "sense of competence", "control of own behavior", "challenging", "belief in positive outcomes", "sharing", and "individuality".

\section{B. Traditional Roles of Jane and Moor}

Jane and Moor held favorable attitudes towards mediation and possessed partial knowledge of situational mediation, but they were traditional instructors owing to the situational constraints related to the current education system, students, and teachers themselves. Moor was the youngest of all the three teachers, but it seemed difficult to find any highlight concerning the current educational reforms in his classroom practices as he instructed the students most conservatively and traditionally. Table 3 summarizes the traditional teaching roles Jane and Moor played. 
TABLE 3

TRADITIONAL ROLES OF JANE AND MOOR

\begin{tabular}{|c|c|c|}
\hline Teacher & Teacher Roles & Main Characteristics \\
\hline Jane & $\begin{array}{l}\text { 1) Teacher-centered } \\
\text { instructor applying } \\
\text { Chinese as a medium of } \\
\text { instruction } \\
\text { 2) Grammar-translation- } \\
\text { based spoon-feeder }\end{array}$ & $\begin{array}{l}\text { 1) Jane tried to control the whole class and make her students "submissive" so that most of them } \\
\text { had no opportunities to regulate their learning. She failed to speak English fluently and employed } \\
\text { Chinese as the medium of instruction. } \\
\text { 2) Jane was skilled at presenting the language points via grammar-translation, but the class could } \\
\text { only write and read English through grammar-translation by sacrificing their listening and } \\
\text { speaking. }\end{array}$ \\
\hline Moor & $\begin{array}{l}\text { 1) Spoon-feeder } \\
\text { 2) Grammar-based } \\
\text { knowledge-transmitter } \\
\text { 3) Non-standard bilingual } \\
\text { speaker }\end{array}$ & $\begin{array}{l}\text { 1) Moor controlled the class and eagerly gave the students answers before their attempts. The } \\
\text { students entirely received knowledge passively. } \\
\text { 2) Moor argued the students could acquire EFL if he transmitted grammar to them. } \\
\text { 3) Moor's poor pronunciation in Mandarin and English was one of the reasons for his not } \\
\text { executing a mediator. }\end{array}$ \\
\hline
\end{tabular}

\section{IMPLICATIONS}

This study is to explore the potential effectiveness of mediation on secondary school EFL classrooms in China for further approaches to make the EFL classroom more mediative. The findings show that most teachers' situational constraints involving the lack of knowledge of mediation prevented them from implementing mediation. The following account suggests solutions to situational constraints the participating teachers encountered from the perspectives of (a) EFL teachers' training programs and (b) the enhancement of students' academic proficiency in EFL.

\section{A. Implications for EFL Teacher Re-education}

From the case studies of three teachers, the two traditional instructors (i.e., Jane \& Moor) were desirous to be trained as mediators since their insufficient knowledge of mediation resulted in the failure of their implementation of mediation. Teachers' re-education is indispensable in conducting mediation since the correct knowledge of mediation was among the prerequisites for the teachers to conduct mediation. Given the findings of the study, updating teachers' EFL proficiency and knowledge of mediation seems to hold great importance.

1) Promotion of teachers' EFL proficiency: China is taking measures to facilitate the re-education of EFL teachers in order to continuously raise the holistic quality of instructional power (National Curriculum, 2000). In 1999, the MOE proposed the execution of teachers' continuing education project for China's secondary schools, whose goals "are to train all the teachers in order to meet the needs of quality education, particularly the training for implementing the new national curriculum....and improving the pedagogical practice" (National Curriculum, 2000, p. 18). Upgrading the subject and pedagogical knowledge of 572,000 secondary school EFL teachers would be expensive and time-consuming, so normal re-training would be short-term intensive seminars and workshops (NBSC, 2008).

The teacher training institutions are mainly composed of in-service teacher training institutes and schools employing teachers (National Curriculum, 2000). This project affected around 550,000 secondary school EFL teachers in China (NBSC, 2008). Post-training teachers' classrooms, however, are still characterized by teacher-centeredness as 'teacher colleges/universities are accustomed to copying comprehensive universities, and taking care of developing discipline knowledge and research, and paying little attention to pedagogical knowledge and abilities" (National Curriculum, 2000, p. 18). In this study, the case of Moor failed to mediate the students' learning though he had been trained for the new Curriculum Standards.

2) Training of MLE knowledge: In the current research, the teachers' knowledge of mediation determined their correct implementation of mediation. It is the first time that mediation theory has been applied in the secondary school Curriculum Standards (MOE, 2001). Previous research has shown that most EFL teachers have little or no exposure to knowledge of mediation (e.g., Grosser \& Waal, 2008; Guo, 2004). For instance, Moor, in this study, who claimed to have learnt mediation at college, was unable to implement mediative functions.

In China's educational setting, "it is not only necessary but also crucial in language teacher education programs to be conducted in the EFL context to achieve an understanding of language teachers' knowledge base to get a sense of where they are, to comprehend their teaching context, and to know their professional development needs" (Cheng \& Wang, 2004, p. 4). Fisher (2005) views teachers' pedagogical knowledge on the implementation of mediation as this "knowledge base" (p. 144). A good command of the 12 MLE tools contributes to teachers re-examining their roles as:

- facilitators for learning content knowledge

- facilitators for learning the process, heuristics, and strategies of learning a particular knowledge field

- mediators of knowledge sources

- mediators of lifelong learning

- mediators of life-wide learning

- designers of the learning environment (Seng et al., 2003, p. 16)

At this point, the challenge for teachers is to use good mediation to design new learning environments, for "as designers of the learning environment, teachers engage students in learning beyond the boundary of the classroom and the immediate human interactions, thus fostering in them independence and a higher level of interdependence" (Seng et al. 2003, pp. 16-17). 


\section{B. Implications for Students' Development in EFL Proficiency}

In this research, the participating teachers complained their students failed to understand their learning tasks assigned in English. They had to talk bilingually, and their students communicated in Chinese. In most cases, the students only listened and took notes when the teacher talked in the class.

The Curriculum Standards encourages students to learn actively and try reducing passive learning through teachercenteredness (MOE, 2001). "So compared to before, teachers talk less during class time", and "this change made some students who were used to relying on teachers' lectures feel that learning had become more difficult" (J. Li, 2004, p. 227). China is a large agriculture-based country with about $70 \%$ of the population living in rural areas, "while members of the Standards writing group and textbook writers are all urban residents" (J. Li, 2004, p. 227). These writers are comparatively acquainted with urban students and ignore the situations and demands of rural students, and even "some teachers have suggested the MOE should provide alternative curricula to teachers of rural students" (J. Li, 2004, p. 227). In this study, for example, most of Moor's students were from rural areas, and the inappropriateness of the Standards contributed to the students' poor English. Probably, the existing curriculum contents need to be developed to relieve the constraints of conducting mediation caused by students' low proficiency in EFL.

In the cases of Jane, many of the students were observed to perform passively towards EFL learning. Brown (2001) suggests as follows:

It seems intuitively clear, nevertheless, that second language learners benefit from positive attitudes and that negative attitudes may lead to decreased motivation and in all likelihood, because of decreased input and interaction, to unsuccessful attainment of proficiency. Yet the teacher needs to be aware that everyone has both positive and negative attitudes. The negative attitudes can be changed, often by exposure to reality--for example, by encounters with actual persons from other cultures. (p. 169)

Ideally, if there are more foreign teachers employed from English-speaking countries, it might be an effective measure to stimulate students' positive attitudes towards EFL learning. Nevertheless, "qualified native English speakers are not common among the teachers of EFL, and Chinese teachers with near-native competence are still not in the majority" (Tang \& Absalom, 2000, p. 124, cited in Y. Yang, 2006, sec. 3). China still has a long way to go in the case of the application of the foreign teacher resource.

In summary, the value of mediating children's learning can never be overemphasized through which the power of children's modifiability should be recognized (Seng et al., 2003). In view of the current instructional environment, many elements restrict teachers' implementation of mediation. These deserve to be lessened until overcome through deeper educational reforms, teachers' efforts, and students' motivation to learn EFL proficiently.

\section{CONCLuSION}

This paper investigated the implementation of mediation among secondary school EFL teachers in China via case studies. Based on the findings, a conclusion is drawn that most secondary school EFL teachers in China were unable to mediate students' learning due to situational constraints caused by the current education system, students, and teachers themselves. In the present educational setting, implementing mediation is theoretically acceptable and practically feasible as illustrated in the case of Alice, but it is challenging for teachers to administer it smoothly because most Chinese EFL learners are weak at English language communication competence. An EFL teacher's command of mediation knowledge plus his/her competence to overcome constraints might result in the successful implementation of mediation strategies in the language classroom. It is proposed that EFL teachers re-orient their roles from traditional instructor to mediator to adapt to the progress of current society. 
Extent of the Teacher's Execution of MLE Features

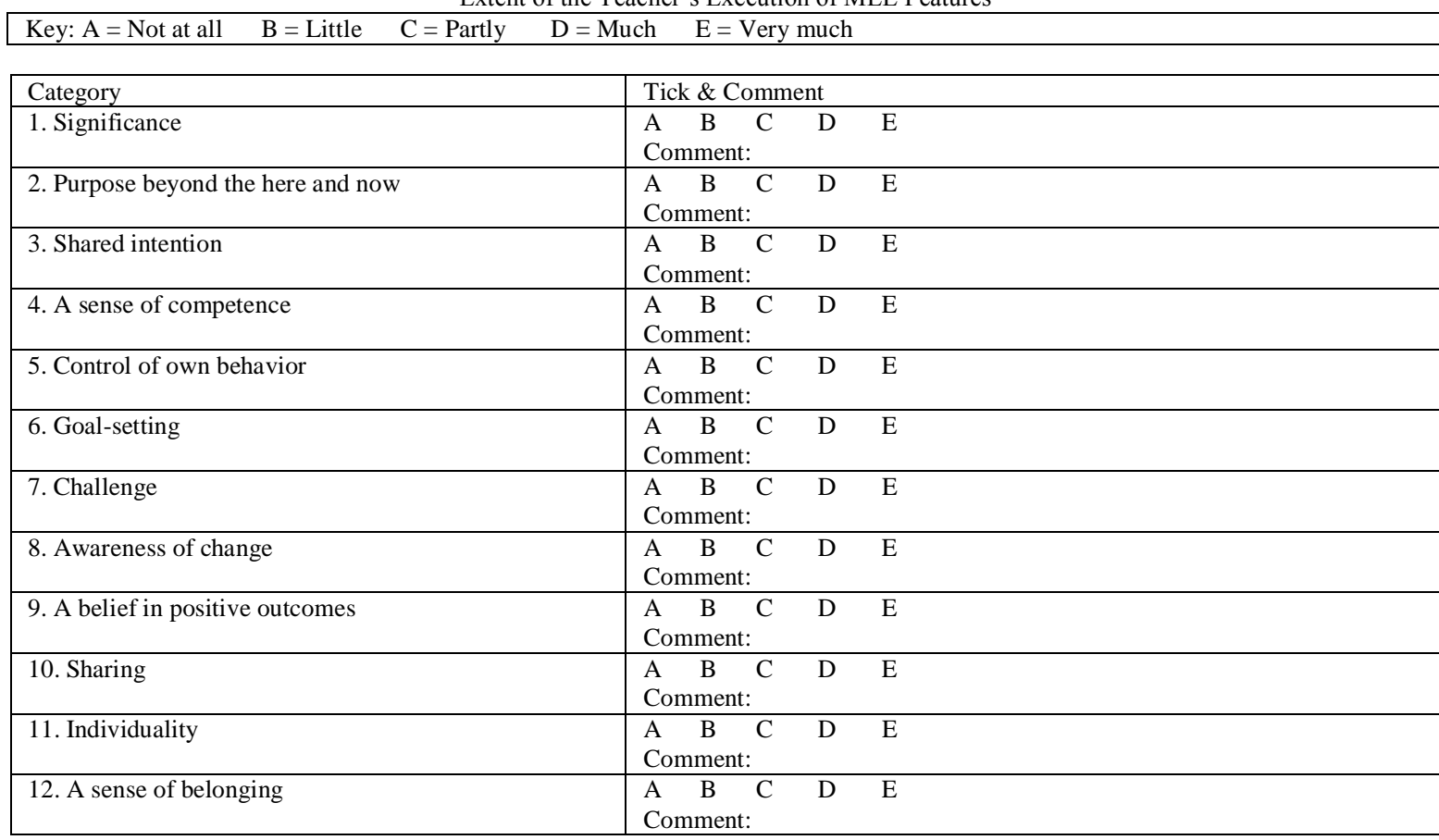

\section{APPENDIX B TEACHER INTER VIEW PROTOCOL}

Semi-structured Interview Questions

1. Please tell me about the observed lesson mainly from the perspective of your own teaching role.

2. Have you received any particular training that supports you to plan in this way? Could you describe it more accurately?

3. Describe, if applicable, your teacher education program from the perspectives as follows:

a. Any central learning that you brought with you from the program into your classroom related to teaching roles.

b. How much of what you know, if any, concerning the mediation role that you learnt as a result of your teacher training, either pre-service or in-service.

4. If, beginning tomorrow, students in China were no longer expected to be confronted with the rigorous entrance exam competition, would you still mediate your EFL classroom, if any, or begin to do it? If so, why and how? If not, why?

5 Could you tell me any difficulties which prevent you from playing the mediation role in the classroom if you are not playing the mediator at present?

6. In what environment do you think EFL learners learn best? Could you offer me some suggestions on how to most effectively implement the role of mediation in China's settings?

\section{REFERENCES}

[1] Brown, H. D. (2001). Principles of language learning and teaching. Beijing: Foreign Language Teaching \& Research Press.

[2] Campione, J. C., Brown, A. L., Ferrara, R. A., \& Bryant, N. R. (1984). The zone of proximal development: Implications for individual differences and learning. In B. Rogoff \& J. V. Wertsch (Eds.), Children's learning in the "zone of proximal development" (pp. 77-91). San Francisco, CA: Jossey-Bass.

[3] Chen, M. L. (2005). The effect of the cooperative learning approach on Taiwanese ESL students' motivation, English listening, reading and speaking competences. Unpublished doctoral dissertation, La Sierra University, California. Retrieved February 12, 2008, from http://proquest.umi.com

[4] Cheng, L. Y., \& Wang, H. (2004). Understanding Professional Challenges Faced by Chinese Teachers of English. Retrieved January 12, 2010, from http://www-writing.berkeley.edu/TESL-EJ/ej28/a2.html

[5] Cheng, X. Y. (2011). Attitudes towards mediation among EFL teachers in China and constraints in their classroom practices. Kaifeng: Henan University Press.

[6] Creswell, J. W. (2005). Educational research: Planning, conducting, and evaluating quantitative and qualitative research (2nd ed.). Upper Saddle River, NJ: Merrill Prentice Hall.

[7] Feuerstein, R. (1980). Instrumental enrichment: An intervention program for cognitive modifiability. Baltimore, MD: Park University Press.

[8] Feuerstein, R. (1990). The theory of structural modifiability. In B. Presseisen (Ed.), Learning and thinking styles: Classroom interaction. Washington, DC: National Education Association.

[9] Fisher, R. (2005). Teaching children to learn (2nd ed.). Cheltenham, UK: Nelson Thornes. 
[10] Fraenkel, J. R., \& Wallen, N. E. (2007). How to design and evaluate research in education (6th ed.). New York, NY: McGrawHill.

[11] Grosser, M., \& Waal, E. (2008). Recentering the Teacher from Transmitter of Knowledge to Mediator of Learning. Retrieved August 29, 2009, from http://108.cgpublisher.com/proposals/569/index_html

[12] Guo, Y. J. (2004). On EFL teachers' mediative functions in terms of facilitating students' initiatives in the classroom. Retrieved August 29, 2009, from http://cdmd.cnki.com.cn/Article/CDMD-10165-2004139087.htm

[13] Hoepfl, M. (1997). Choosing qualitative research: A primer for technology education researchers. Journal of Technology Education, 9 (1). Retrieved September 18, 2009, from http://scholar.lib.vt.edu/ejournals/JTE/v9n1/pdf/hoepfl.pdf

[14] Kang, S. M., \& Wang, X. M. (2003). Improve college English teaching with multimedia. Retrieved December 23, 2007, from http://www.etc.sjtu.edu.cn/zazi/paper/04101/04157.html

[15] Lai, D. L. (2004). A survey of mediative functions of Chinese secondary school EFL teachers. Foreign Language Teaching Research for Basic Education. Beijing, China: Foreign Language Teaching \& Research Press.

[16] Lantolf, J. P. (2000). Introducing sociocultural theory. In J. P. Lantolf (Ed.), Sociocultural theory and second language learning. Oxford, UK: Oxford University Press.

[17] Larsen-Freeman, D. (2000). Techniques and principles in language teaching (2nd ed.). Oxford, UK: Oxford University Press.

[18] Lewin, K., Little, A., Xu, H., \& Zheng, J. (1994). Educational innovation in China: Tracing the impact of the 1985 reforms. Essex, UK: Longman.

[19] Li, J. (2004). Statistics education for junior high schools in China. Curriculum Development in Statistics Education, p. 219. Retrieved August 12, 2009, from http://www.stat.auckland.ac.nz/ iase/publications/rto04/5.2_Li.pdf

[20] Li, Y. (2004). Chinese teachers' perceptions of the implementation and effectiveness of communicative language teaching. Unpublished master's thesis, Memorial University of Newfoundland, Canada. Retrieved March 20, 2008, from http://proquest.umi.com

[21] Liao, X. (2003). Chinese secondary school teachers' attitudes towards communicative language teaching and their classroom practices. Unpublished doctoral dissertation, University of Auckland, New Zealand. Retrieved February 12, 2008, from http://proquest.umi.com

[22] Merriam, S. B. (1998). Qualitative research and case study applications in education. San Francisco, CA: Jossey-Bass.

[23] Ministry of Education of China. (2001). Guojia jichu jiaoyu yingyu kecheng biaozhun (3-12 nianji) (shiyangao) [National standards of English curriculum for China's basic education (trial)]. Beijing: Beijing Shifan Daxue Chubanshe [Beijing Normal University Press]. Translated by the American Department of Education. Retrieved February, 8, 2008, from http://hrd.apecwiki.org/index.php/Language_Content_Standards

[24] National Bureau of Statistics of China. (2008). China statistical yearbook 2008. Beijing: China Statistics Press.

[25] National curriculum for basic education in the People's Republic of China. (2000). Retrieved March, 1, 2009, from http://www.ibe.unesco.org/curriculum/Asia\%20Networkpdf/CHINA.pdf

[26] Ng, C., \& Tang, E. (1997). Teachers' needs in the process of EFL reform in China: A report from Shanghai. Perspectives, 9(1), 63-85.

[27] Palincsar, A. S. (1998). Social constructivist perspectives on teaching and learning. In J. T. Spence, J. M. Darley, \& D. J. Foss (Eds.), Annual review of psychology (pp. 345-375). Palo Alto, CA: Annual Reviews.

[28] Paris, S. G., Byrnes, J. P., \& Paris, A. H. (2001). Constructing theories, identities, and actions of self-regulated learners. In B. J. Zimmerman \& D. H. Schunk (Eds.), Self-regulated learning and academic achievement: Theoretical perspectives (2nd ed., pp. 252-287). Mahwah, NJ: Erlbaum.

[29] Phillips, D. (1997). How, why, what, when, and where: Perspectives on constructivism and education. Issues in Education: Contributions from Educational Psychology, 3, 151-194.

[30] Schunk, D. H. (2000). Learning theories: An educational perspective (3rd ed.). Upper Saddle River, NJ: Prentice Hall.

[31] Seng, A. S. H., Pou, L. K. H., \& Tan, O. S. (2003). Mediated learning experience with children. Singapore: McGraw-Hill.

[32] Shen, H. X. (2008). Teacher's role-as-mediator in the EFL classroom. Unpublished master's thesis on-line. Retrieved August 29, 2009, from http://www.lunwenjia.com/waiguoyuyan/417160.html

[33] Stake, R. E. (1978). The case study method in social inquiry. Educational Researcher, 7(2), 5-8.

[34] Sun, Y. (2007). The mediation of junior high school English teachers in the student's autonomous learning. Unpublished master's thesis, Northeast Normal University, China. Retrieved August 30, 2009, from http://www.shwanfangdata.com/WFknowledgeServer_Mirror/D/Thesis_Y1202116.aspx

[35] Vasireddy, P. (2007). Learning theories. Retrieved November $20, \quad 2008$, from http://www.cs.lit.edu/ cs561/spring2007/LearningTheories/VasireddyPavankumarLearningTheories.pdf

[36] Vygotsky, L. (1978). Mind in society: The development of higher psychological process. Cambridge, MA: Harvard University Press (Original work published in 1930-33).

[37] Williams, M., \& Burden, R. L. (2000). Psychology for language teachers: A social constructivist approach. The People's Education Press, Foreign Language Teaching and Research Press, and Cambridge University Press.

[38] Woolfolk, A. E. (2004). Educational psychology (9th ed.). Englewood Cliffs, NJ: Pearson.

[39] Yang, H. T. (2006). A survey of EFL teachers' meditative functions. Foreign Language Field, 19(3), 25-31.

[40] Yang, Y. (2006). EFL teachers in Chinese public schools: Reflections and suggestions on their needs. Retrieved January 18, 2010, from http://www.tesol.org/NewsletterSite/view.asp?nid=2982

[41] Yang, Z. (2003). Teacher professionalism and professional development of EFL teachers in China. Retrieved October 6, 2009, from http://www.tefl-china.net/2003/ca13425.htm

[42] Ye, J. (2007). Adapting communicative language teaching approach to China's context. Sino-US Teaching, 4(10) (Serial No. 46), USA.

[43] Zeng, P. (2005). Teacher evaluation in Chinese elementary schools: A historical account. Unpublished doctoral dissertation, Brigham Young University. Retrieved October 4, 2009, from http://contentdm.lib.byu.edu/ETD/image/etd1129.pdf 


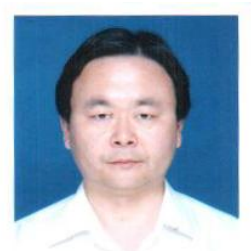

Xiongyong Cheng was born in Xinyang, China in 1966. He is an associate professor in teaching English as a Foreign Language (EFL) at the Department of Foreign Languages, Xinyang Agricultural College, China. His primary research interests are EFL testing and assessment in relation to classroom instruction. He holds an MA in Teaching English as a Foreign Language (TEFL) from Henan Normal University, China, and a PhD in Teaching English as a Second Language (TESL) from the University of Malaya, Malaysia.

His current research interests encompass EFL teaching, inter-cultural communication, teacher education, professional development, and the evaluation of curriculum implementation.

Assoc. Prof. Dr. Cheng was awarded the honor title "National Excellent Education Gardener" by the Ministry of Education of China.

Hua Cheng was born in Xinyang, China in 1990. She is currently a BA candidate in Teaching English as a Foreign Language (TEFL) at the Faculty of Foreign Languages, Henan University Minsheng College, China. Her primary research interests are TEFL education and teacher training assessment related to classroom instruction.

Her current research interests involve TEFL teaching, American and British literature, and English language linguistics as well.

Ms Cheng was awarded the honor title "Henan Provincial Excellent College Student" by the Education Department of Henan Province, China. 